\title{
THD Minimization from H-Bridge Cascaded Multilevel Inverter Using Particle Swarm Optimization Technique
}

\author{
MUDASIR AHMED MEMON*, SHAHZAD MEMON*, AND SHARIQ KHAN** \\ RECEIVED ON 14.07.2015 ACCEPTED ON 14.12.2015 \\ ABSTRACT
}

\begin{abstract}
In this paper, PSO (Particle Swarm Optimization) based technique is proposed to derive optimized switching angles that minimizes the THD (Total Harmonic Distortion) and reduces the effect of selected low order non-triple harmonics from the output of the multilevel inverter. Conventional harmonic elimination techniques have plenty of limitations, and other heuristic techniques also not provide the satisfactory results. In this paper, single phase symmetrical cascaded H-Bridge 11-Level multilevel inverter is considered, and proposed algorithm is utilized to obtain the optimized switching angles that reduced the effect of $5^{\text {th }}, 7^{\text {th }}, 11^{\text {th }}$ and $13^{\text {th }}$ non-triplen harmonics from the output voltage of the multilevel inverter. A simulation result indicates that this technique outperforms other methods in terms of minimizing THD and provides high-quality output voltage waveform.
\end{abstract}

Key Words: Heuristic Techniques, Switching Angles, Particle Swarm Optimization, Total Harmonic Distortion, Multilevel Inverter.

\section{INTRODUCTION}

$\mathrm{M}$ ultilevel inverter is an electronic power converter device used to drive AC power applications which require high voltage and high power ratings. Most of the researchers and academics in power electronics field are engaged in this research to optimize the performance of multilevel inverters [1]. Conventional inverters output contains only 2 DC levels that results in higher switching losses, EMI (Electromagnetic Interference) and harmonic distortion [2]. Due to harmonics, current may increase in the system which results in heating and additional losses, ultimately that shortens the life of devices. To counter these limitations, multilevel inverters were introduced. The term multilevel represents the output voltage, which is composed of different constant DC voltage levels that results in a sinusoidal output voltage waveform. Through this technique, smooth sinusoidal waveform is achieved with reduced harmonics and lesser EMI. The harmonic distortion in the waveform of multilevel inverter output is inversely proportional to the level of the inverter and it approaches zero when levels are infinite [2].

The three main types of multilevel Inverters are Flying Capacitors, Cascaded H-Bridge and Diode Clamped. The Cascade H-Bridge topology requires less number of components and has high reliability. Due to its simple repetitive structure, it is flexible in situations where addition or removal of any level is required [2]. In addition,

* Institute of Information \& Communication Technology, University of Sindh, Jamshoro.

** College of Engineering, Design \& Physical Sciences, Brunel University, London, UK.

Mehran University Research Journal of Engineering \& Technology, Volume 36, No. 1, January, 2017 [p-ISSN: 0254-7821, e-ISSN: 2413-7219] 
different switching modulation techniques were introduced and used to reduce the harmonics distortion from the fundamental waveform. The SPWM (Sinusoidal or "Subharmonic" Natural Pulse Width Modulation), OHSW (Optimized Harmonic Stepped-Waveform) and SHEPWM (Selective Harmonic Eliminated Pulse Width Modulation) are the main modulation techniques which are discussed in the literature [3] to eliminate harmonics from multilevel inverters.

In all above mentioned techniques, the SHEPWM has been widely used due to its ability to operate in lower switching frequencies which makes it suitable for high power applications [4]. SHEPWM technique only eliminates specific unwanted lower-order harmonic components from the output of single or three-phase inverters and it is based on optimized switching angles. So, the selection of appropriate angles plays a significant role for healthy power conversion that result in distorted less output. In three phase system, triplen harmonics like $\left(3^{\text {rd }}, 9^{\text {th }}\right.$, and $\left.15^{\text {th }}\right)$ are automatically eliminated from line to line voltage so there is no need of adding these in transcendental equations [13].

Nowadays, heuristic algorithms like GA (Genetic Algorithm), PSO and ACO (Ant Colony Optimization), are under research to find optimized angles [5]. The PSO algorithm is an iterative method based on cooperative actions of different animal and species like fishes and birds, and it was developed by Russell C. Eberhart and James Kennedy in 1995. The word "Particle" refers to the individual bird, and each particle has a solution which compared by others particles to find optimum solution of any given problem [6]. Five heuristic methods MA (Memetic Algorithm), ACO, GA, SFL, and PSO were compared by [7] and observed that the solution quality and success rate of PSO is better than other algorithms.

The basic PSO algorithm is consists of two equations. The updated velocity of a particle is determined by Equation (1) and updated position of a particle is derived from Equation (2).

$v_{i j}^{t+1}=\left\lfloor v_{i j}^{t} \times \omega^{t+1}\right\rfloor+\left\lfloor c_{1} \times r_{1 j}^{t} \times\left\lfloor P_{\text {best. } i}^{t}-x_{i j}^{t}\right\rfloor \mid+\left\lfloor c_{2} \times r_{2 j}^{t} \mid G_{\text {best }}-x_{i j}^{t}\right\rfloor\right.$ $v_{i j}^{t+1}=x_{i j}^{t}+v_{i j}^{t+1}$

The term $\omega^{\mathrm{t}+1}$ is the inertia, and it linearly decreases from 0.9-0.4 and it is represented by Equation (3).

$\omega^{t+1}-\omega_{\max }-\left[\frac{\omega_{\max }-\omega_{\min }}{\text { Total Number of Iterations }} \times\right.$ Current Iteration $]$

The term personal best $\left[\mathrm{P}^{\mathrm{t}}{ }_{\text {best,ij }}\right]$ is the personal best position or personal experience of particle " $\mathrm{i}$ " in " $\mathrm{j}$ " direction, and the term Global best $\left[\mathrm{G}_{\text {best }}\right]$ is the position of a particle which is nearer to the target or have the best solution (fitness) among all particles present in the swarm or cluster. The term $\mathrm{x}_{\mathrm{ij}}^{\mathrm{t}}$ is the present position of particle " $\mathrm{i}$ " at time " $t$ " in " $\mathrm{j}$ " direction. The acceleration constants $\mathrm{c}_{1}$ and $\mathrm{c}_{2}$ are used to control the influence of swarm experience and personal experience on future velocity, and they are normally selected in between ( 0 and 2$)$, whereas $\mathrm{r}_{1 \mathrm{j}}^{\mathrm{t}}$ and $\mathrm{r}_{2 \mathrm{j}}^{\mathrm{t}}$ are numbers randomly generated in between $(0$ and 1$)$ [8].

\section{COMPARISON OF DIFFERENT HEURISTIC TECHNIQUES}

The solution of SHEPWM contains non-linear transcendental equations. These equations were solved by numerical iterative methods including NR (NewtonRaphson) and Resultant Theory. However, these methods are very complex and time-consuming and their success depends on good initial guess [5]. The optimization algorithms used in the literature are GA, ACO, ANN (Artificial Neural Network), SA (Simulated Annealing) and BCO (Bee Colony Optimization). Table 1 contains the summary of all heuristic methods used for harmonics elimination from the multilevel inverter.

GA produced optimized switching angles but it wastes a lot of time to calculate optimized angles.

\section{H-BRIDGE CASCADED MULTILEVEL INVERTER}

The universal structure of H-Bridge cascaded multilevel is shown in Fig. 1 and the output voltage waveform

Mehran University Research Journal of Engineering \& Technology, Volume 36, No. 1, January, 2017 [p-ISSN: 0254-7821, e-ISSN: 2413-7219] 
obtained from 11-level H-Bridge cascaded multilevel is shown in Fig. 2. The cascaded H-Bridge multilevel inverter is based on numerous H-Bridge inverters that are coupled in a sequence. The numbers of output voltage levels are dependent on switching angles $(\mathrm{S})$ or number of DC sources and it is formulated by $(2 \mathrm{~S}+1)$. Fig. 2 represents the output voltage waveform of the 11-level multilevel inverter with five different optimized switching angles $\left(\theta_{1}, \theta_{2}, \theta_{3}, \theta_{4}, \theta_{5}\right)$ having five separate DC sources $\left(\mathrm{v}_{\mathrm{dc} 1}, \mathrm{v}_{\mathrm{dc} 2}, \mathrm{v}_{\mathrm{dc} 3}, \mathrm{v}_{\mathrm{dc} 4}, \mathrm{v}_{\mathrm{dc} 5}\right)^{*}$ The voltage sources can be symmetrical (equal) or Asymmetrical (unequal).

The output voltage waveform of multilevel inverter is represented through Fourier Series expansion by Equation (4) [5]:

$$
v(w t)=\sum_{n=1}^{\infty} v_{n} \sin (n w t)
$$

Where $v_{n}$ is the magnitude of harmonics $\left(v_{1}, v_{5}, v_{7} \ldots . v_{n}\right)$ and it is represented by Equation (5):

$v_{n}=\left\{\begin{array}{cc}\frac{4}{n \pi} \times \sum_{k=1}^{s}\left[v_{d c} \cos \left(n \theta_{k}\right)\right] & \text { For odd ns } \\ 0 & \text { For even ns }\end{array}\right.$

Where $0<\theta_{1}<\theta_{2}<\ldots \theta_{\mathrm{k}}<\pi / 2$

The Selective harmonic elimination method deals with Equation (5) that reduces or eliminates desired low order harmonics from the output voltage waveform of the multilevel inverter. In this paper, single phase11-level symmetrical cascaded H-Bridge multilevel inverter is under study to decrease the effect of $5^{\text {th }}, 7^{\text {th }}, 11^{\text {th }}$ and $13^{\text {th }}$ harmonics from the output voltage waveforms. Thus for the proposed inverter the set of transcendental equations are formed as Equation (6) [4]. The first line in Equation (6) represents the fundamental waveform which is desirable and rest of the equations are representing $5^{\text {th }}$, $7^{\text {th }}, 11^{\text {th }}$ and $13^{\text {th }}$ harmonics voltages which must be eliminated from the output waveform of the multilevel inverter that's why they are equal to zero.
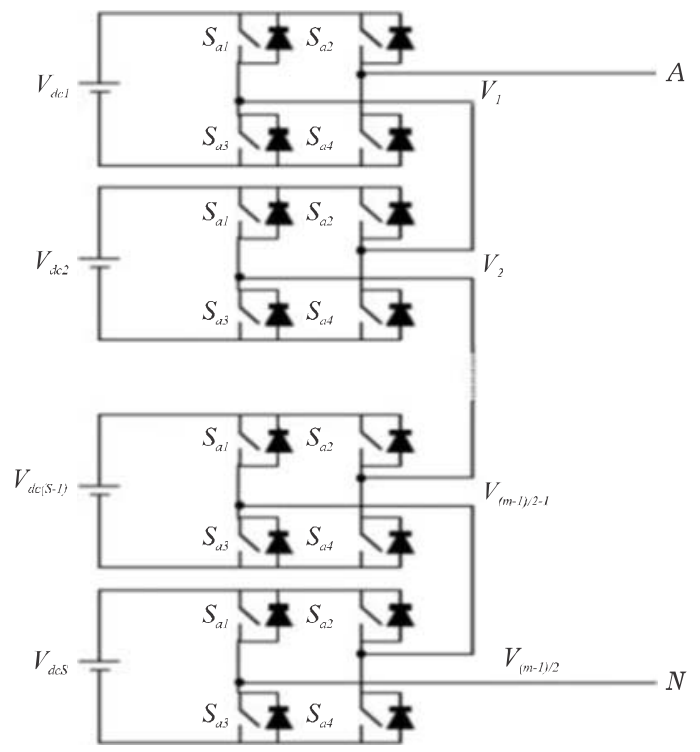

FIG. 1. UNIVERSAL ARRANGEMENT OF SINGLE PHASE CASCADED H-BRIDGE MULTILEVEL INVERTER

TABLE 1. HARMONICS ELIMINATION USING HEURISTIC METHODS

\begin{tabular}{|c|c|c|c|c|}
\hline Proposed Method & Levels & Harmonics & Features & Limitations \\
\hline Artificial Neural Network [9] & $\begin{array}{c}\text { 7-level } \\
\text { 11-level }\end{array}$ & $5,7,11,13$ & $\begin{array}{c}\text { 7-level=14.57\% THD } \\
\text { 11-level=9.79\% THD }\end{array}$ & $\begin{array}{c}\text { ANN produce high } \\
\text { THD } \% \text { compare to GA }\end{array}$ \\
\hline Bee Colony Optimization [5] & 7-level & 5,7 & THD=9.57\% & $\begin{array}{c}\text { BCO produce High } \\
\text { THD } \% \text { compare to GA }\end{array}$ \\
\hline $\begin{array}{c}\text { Comparison of Newton- } \\
\begin{array}{c}\text { Raphson and Genetic } \\
\text { Algorithm [4] }\end{array}\end{array}$ & 7-levels & $3,5,7$ & $\begin{array}{c}\text { THD (NR) }=11.68 \% \\
\text { THD (GA) }=6.61 \%\end{array}$ & GA consume High Time \\
\hline $\begin{array}{c}\text { Simulated Annealing Algorithm } \\
\text { [10] }\end{array}$ & 9-level & 5,7 & $\begin{array}{c}\mathrm{THD}=8.99 \% . \\
\text { Consume less time } \\
\text { compare to GA }\end{array}$ & $\begin{array}{c}\text { SA algorithm produces high } \\
\text { THD } \% \text { compare to GA. }\end{array}$ \\
\hline Newton Raphson [11] & 11-level & $5,7,11,13$ & $\begin{array}{c}\text { THD }=4 \% \\
\text { Consume more time Compare } \\
\text { to heuristic technique }\end{array}$ \\
\hline
\end{tabular}

Mehran University Research Journal of Engineering \& Technology, Volume 36, No. 1, January, 2017 [p-ISSN: 0254-7821, e-ISSN: 2413-7219] 
$\cos \theta_{1}+\cos \theta_{2}+\cos \theta_{3}+\cos \theta_{4}+\cos \theta_{5}=5 \times M$

$\cos 5 \theta_{1}+\cos 5 \theta_{2}+\cos 5 \theta_{3}+\cos 4 \theta_{4}+\cos 5 \theta_{5}$

$\cos 7 \theta_{1}+\cos 7 \theta_{2}+\cos 7 \theta_{3}+\cos 7 \theta_{4}+\cos 7 \theta_{5}$

$\cos 11 \theta_{1}+\cos 11 \theta_{2}+\cos 11 \theta_{3}+\cos 11 \theta_{4}+\cos 11 \theta_{5}=0$

$\cos 13 \theta_{1}+\cos 13 \theta_{2}+\cos 13 \theta_{3}+\cos 13 \theta_{4}+\cos 13 \theta_{5}=0$

Where $\mathrm{M}$ is the modulation index that is defined by the Equation (7) and formula for total harmonic distortion is represented by Equation (8) [12].

$$
\begin{aligned}
& M=\frac{v_{1} \times \pi}{4 \times S \times v_{d c}} \quad 0<\mathrm{M}<1 \\
& T H D \%=\frac{\sqrt{n \sum_{5,7,11,13}^{n} v_{n}^{2}}}{v_{1}} \times 100
\end{aligned}
$$

\section{PROPOSED TECHNIQUE}

In this section, the methodology of proposed algorithm has been discussed in detail. The flow chart of proposed system is shown in Fig. 3. First step is the initialization of population with each sets of five random angles $\left(0<\theta_{1}<\right.$ $\theta_{2}<\theta_{3}<\theta_{4}<\theta_{5}<\pi / 2$ ), c1, c2, modulation index, and inertia weight. Then calculate the fitness of each agent defined in Equation (9) for reduction of the desired harmonic from 11-level cascaded multilevel inverter. The fitness function is designed in such way that it minimizes $5^{\text {th }}, 7^{\text {th }}, 11^{\text {th }}$ and $13^{\text {th }}$ harmonics from the output of the multilevel inverter and maintains the fundamental voltage at desirable level.

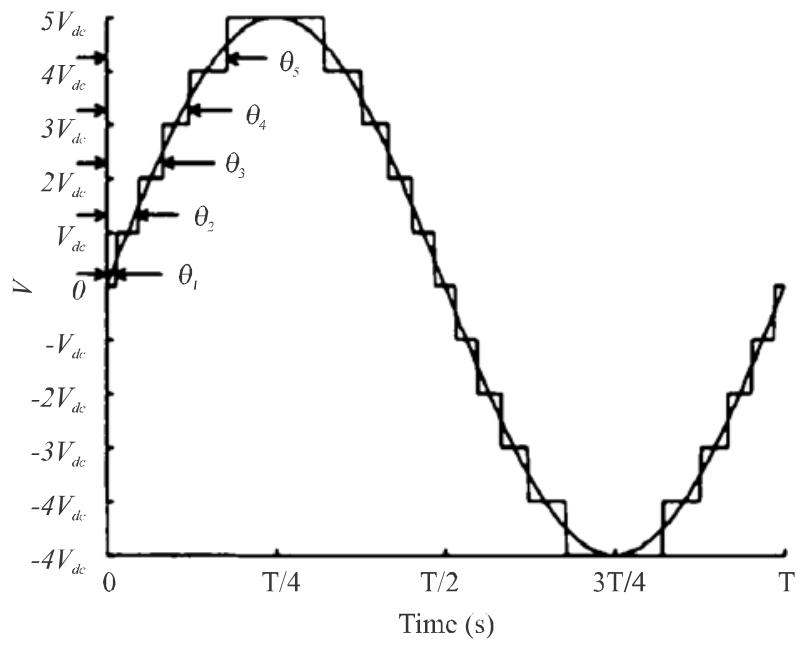

FIG. 2. OUTPUT VOLTAGE WAVEFORM OF 11-LEVEL MULTILEVEL INVERTER
$F\left(\theta_{1}, \theta_{2}, \theta_{3}, \theta_{4}, \theta_{5}\right)=\left|\frac{V_{5}}{V_{1}}\right|+\left|\frac{V_{7}}{V_{1}}\right|+\left|\frac{V_{11}}{V_{1}}\right|+\left|\frac{V_{13}}{V_{1}}\right|+\left|\frac{V_{\text {Desired }}-V_{1}}{V_{\text {Desired }}}\right|$

Where $\mathrm{V}_{\text {Desired }}$ is the desired output voltage. Calculate personal best $\left(\mathrm{P}_{\text {best }}\right)$ and Global best $\left(\mathrm{G}_{\text {best }}\right)$ values of individual agent and for whole the swarm, respectively. Update the current position (angle) and velocity of each particle using Equations (2) and (1), respectively.

After finding the angle set of each population, check whether they are in ascending order and also bound in

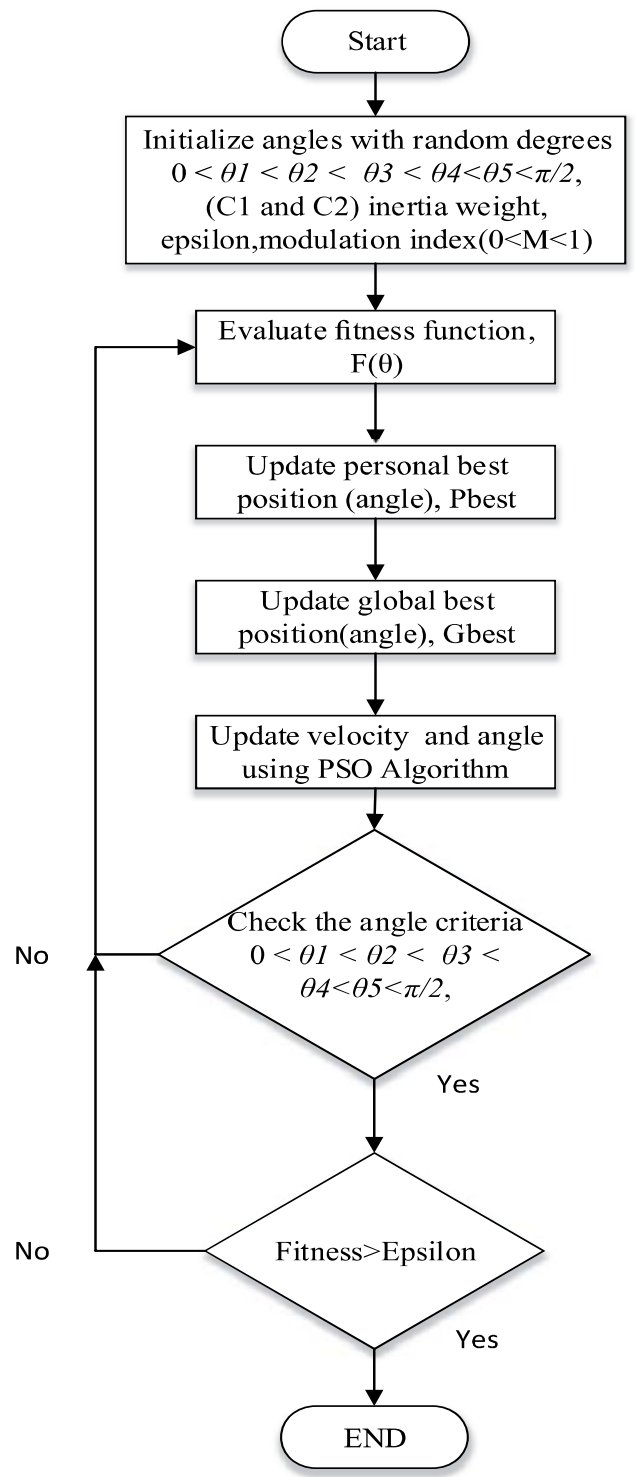

FIG. 3. PROPOSED PSO (PARTICLE SWARM OPTIMIZATION) ALGORITHM

Mehran University Research Journal of Engineering \& Technology, Volume 36, No. 1, January, 2017 [p-ISSN: 0254-7821, e-ISSN: 2413-7219] 
between $(0$ and $\pi / 2)$, otherwise repeat the process from fitness calculation without updating the angles. Check the termination condition (epsilon) in each iteration and repeat the whole process for the modulation index $(0-1)$ with the step of 0.01 .

\section{SIMULATION RESULTS AND DISCUSSIONS}

The result of optimized switching angles obtained from a proposed system that reduces the selected low order harmonics and minimizes THD\% from single phase symmetric 11-level cascaded H-Bridge multilevel inverter with five separate DC sources are listed in Table 2 for modulation index 0-1.

The proposed algorithm produces suitable switching patterns which minimized THD for the whole range of modulation index. At 0.91 , the proposed algorithm gives the minimum THD. The proposed algorithm effectively reduces the $5^{\text {th }}, 7^{\text {th }}, 11^{\text {th }}$ and $13^{\text {th }}$ harmonics from the single phase symmetrical H-Bridge cascaded 11-level inverter. The patterns of switching angles for varying modulation index 0 to 1 with a step of 0.01 are shown in Fig. 4. Fig. 5 represents the response of proposed algorithm by varying modulation index and THD of the system.

Fig. 6 represents the magnitude of each harmonic order calculated at the modulation index 0.91. From Fig. 6 it is proved that proposed algorithm successfully reduced selected non-triplen harmonics from single phase inverter and provides healthy output voltage waveform.

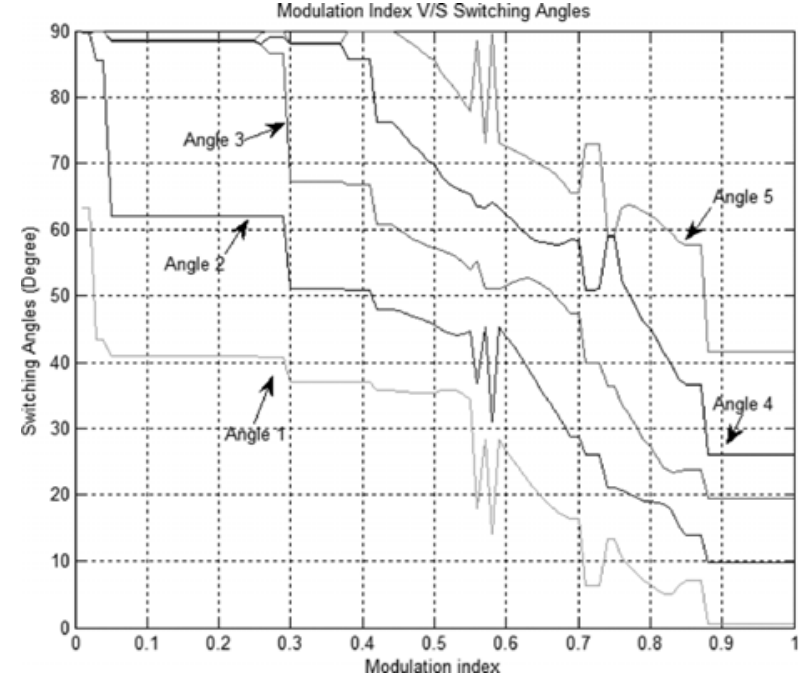

FIG. 4. MODULATION INDEX V/S SWITCHING ANGLES

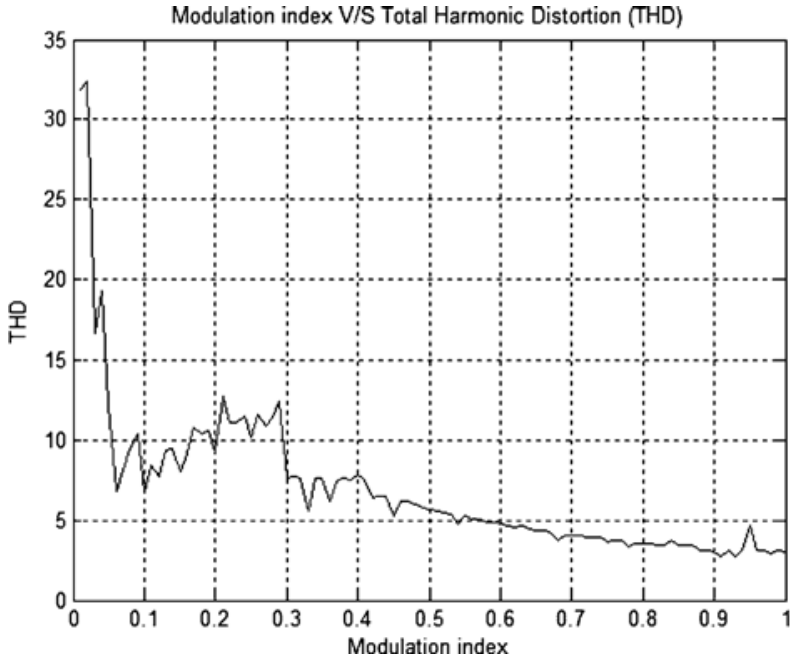

FIG. 5. THD V/S MODULATION INDEX

TABLE 2: SWITCHING ANGLES AT VARIOUS MODULATION INDEX (M)

\begin{tabular}{|c|c|c|c|c|c|c|}
\hline \multirow{2}{*}{ Modulation Index } & \multicolumn{5}{|c|}{ Switching Angles (Degrees) } & \multirow{2}{*}{ THD (\%) } \\
\hline & $\theta_{1}$ & $\theta_{2}$ & $\theta_{3}$ & $\theta_{4}$ & $\theta_{5}$ & \\
\hline 0.1 & 40.860 & 62.209 & 88.504 & 88.509 & 88.651 & 6.68 \\
\hline 0.2 & 40.860 & 62.209 & 88.503 & 88.509 & 88.652 & 9.29 \\
\hline 0.3 & 36.972 & 51.164 & 67.199 & 87.983 & 88.243 & 7.58 \\
\hline 0.4 & 36.915 & 50.960 & 66.827 & 85.791 & 89.999 & 7.85 \\
\hline 0.5 & 35.526 & 45.4940 & 57.204 & 69.202 & 84.926 & 5.69 \\
\hline 0.6 & 26.554 & 43.844 & 51.553 & 62.348 & 72.471 & 4.74 \\
\hline 0.7 & 8.175 & 28.516 & 41.246 & 53.333 & 73.328 & 4.06 \\
\hline 0.8 & 6.4198 & 18.909 & 26.889 & 44.837 & 62.100 & 3.5 \\
\hline 0.9 & 0.448 & 9.863 & 19.391 & 26.050 & 41.578 & 3.05 \\
\hline 0.91 & 0.466 & 9.861 & 19.392 & 26.050 & 41.578 & 2.74 \\
\hline 1.0 & 0.424 & 9.865 & 19.390 & 26.050 & 41.578 & 3.05 \\
\hline
\end{tabular}

Mehran University Research Journal of Engineering \& Technology, Volume 36, No. 1, January, 2017 [p-ISSN: 0254-7821, e-ISSN: 2413-7219] 


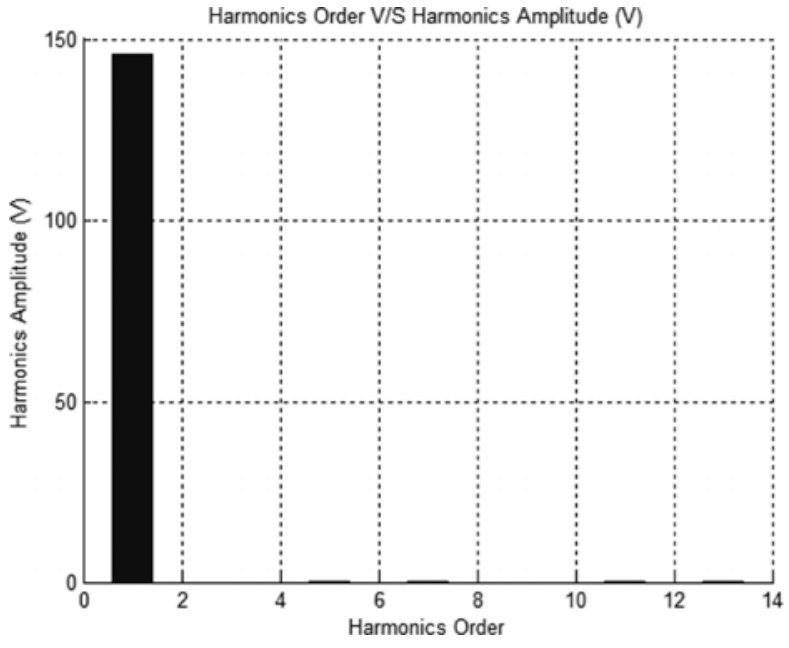

FIG. 6. HARMONIC ORDERS OF OUTPUT VOLTAGE WAVEFORM

\section{CONCLUSION}

In this paper, A PSO-based approach was proposed to reduce the effect of non-triplen harmonics $\left(5^{\text {th }}, 7^{\text {th }}, 11^{\text {th }}\right.$, and $13^{\text {th }}$ ) from single phase 11-level symmetrical cascaded $\mathrm{H}$-Bridge multilevel inverters. Simulation results indicate that the proposed algorithm produced less THD and provide satisfactory results as compared to other techniques discussed in the literature. The proposed technique reduces THD up-to $2.74 \%$, however; the proposed technique require further research to minimize THD to improve the output voltage quality of a multilevel inverter

\section{ACKNOWLEDGMENT}

Authors are thankful to the Institute of Information \& Communication Technology, University of Sindh, Jamshoro, Pakistan, for providing electronics laboratory and digital library access facility to accomplish this research.

\section{REFERENCES}

[1] Kouro, S., and Malinowski, M., "Recent Advances and Industrial Applications of Multilevel Converters", IEEE Transactions on Industrial Electronics, Volume 57, No. 8, pp. 2253-2580, August, 2010.

[2] Naveena, J., and Ramraj, B., “An Advanced Topology for Cascade Multilevel Inverter Based on Developed HBridge", International Journal of Engineering Research and General Science, Volume 2, No. 6, pp. 259-265, 2014.
Singh, B., Mittal, N., Verma, K.S., Singh, D., Singh, S.P., Dixit, R., Singh, and Baranwal, A., "Multi-Level Inverter: A Literature Survey on Topologies and Control Strategies", International Journal of Reviews in Computing, Volume 10, pp. 1-16, July, 2012.

Parkash, A., Shimi, S.L., and Chatterji, S., "Harmonics Elimination in Cascade Multilevel Inverters Using Newton-Raphson and Genetic Algorithm", International Journal for Scientific Research \& Development, Volume 2, No. 5, pp. 236-239, 2014.

Priya, S.G., Sasikala, R., and Meenakumari, R., "A Metaheuristic Approach for Cascaded Multilevel Inverters to Improve Power Quality", International Electrical Engineering Journal, Volume 5, No. 4, pp. 1313-1320, 2014.

Mahant, M., choudhary, B., Kesharwani, A., and Rathore, K.S., "A Profound Survey on Swarm Intelligence", International Journal of Advanced Computer Research, Volume 2, pp. 31-36, 2012.

Elbeltagi, E., Hegazy, T., and Grierson, D., "Comparison among Five Evolutionary-Based Optimization Algorithms", Advanced Engineering Informatics, Volume 19, pp. 43-53, 2005.

Talukder, S., "Mathematical Modelling and Applications of Particle Swarm Optimization", M.S Thesis, School of Engineering Blekinge Institute of Technology Karlskrona, Sweden, 2010.

[9] Shrivastava, M., "Comparative Analysis of PWM Techniques for Multilevel Inverter Control Using ANN", International Journal of Computer Applications, Volume 46, No. 19, pp. 20-24, May, 2012.

[10] Sugumaran, G., Vinothkumar, L., Isvariya, A., and Janardhanan, M., "Simulated Anealing Algorithm Based Optimization for Cascaded Multilevel Inverters", International Journal on Applications in Electrical and Electronics Engineering, Volume 1, No. 1, pp. 32-35, January, 2015.

[11] Kumar, D.J., "THD Analysis for Different Levels of Cascade Multilevel Inverters for Industrial Applications", International Journal of Emerging Technology and Advanced Engineering, Volume 2, No. 10, October, 2012.

[12] Adeyemo, I.A., Aborisade, D.O., and Ojo, J.A., "Selective Harmonic Elimination in Multilevel Inverter Using Real Coded Genetic Algorithm Initialized Newton Raphson Method", International Journal of Engineering Research \& Technology, Volume 2, No. 9, pp. 3107-3113, September, 2013.

[13] Taghizadeh, H., and Hagh, M.T., "Harmonic Elimination of Cascade Multilevel Inverters with No Equal DC Sources Using Particle Swarm Optimization", IEEE Transactions on Industrial Electronic, Volume 57, No. 11, pp. 3678-3684, 2010. 